\title{
ANALISIS STABILITAS LERENG MENGGUNAKAN PROGRAM GEO5
}

\author{
Welliam Pattinasarany \\ Program Study Teknik Sipil Universitas Muhammadiyah Sorong \\ Jalan Pendidikan No 27 Kota Sorong, Propinsi Papua Barat \\ Email : willipattinasarany@gmail.com
}

\begin{abstract}
ABSTRAK
Kota Sorong adalah sebuah Kota di Provinsi Papua Barat Indonesia kota ini dikenal dengan sebutan kota minyak. sangatlah strategis karena merupakan pintu keluar masuk dan transit ke Papua Barat. Pesatnya pembangunan di daerah perkotaan dan besarnya keinginan masyarakat untuk memiliki kediaman dan rumah peristirahatan di dataran tinggi menyebabkan pembangunan di daerah lereng tidak dapat di hindari lagi. Daerah seperti ini sangat rentan terhadap keruntuhan atau longsor yang dapat menimbulkan berbagai kerugian, untuk itu kestabilan lereng yang akan digunakan perlu di teliti. Lereng yang terletak di jalan Selat Karimata belakang Hotel Pilihan Kota Sorong merupakan salah satu area yang letaknya di atas permukiman warga. Tujuan penilitian ini yaitu untuk menganalisis stabilitas lereng untuk mengetahui tingkat keamanan dari lereng tersebut. Metode penilitian ini yang digunakan adalah perhitungan manual dan program
\end{abstract}

KATA KUNCI : kota sorong, anlisis stabilitas lereng, program Geo5 


\section{PENDAHULUAN}

\section{Latar Belakang}

Kota Sorong adalah sebuah Kota di Provinsi Papua Barat Indonesia kota ini dikenal dengan sebutan kota minyak. Kota Sorong sangatlah strategis karena merupakan pintu keluar masuk dan transit ke Papua Barat. Pesatnya pembangunan di daerah perkotaan dan besarnya keinginan masyarakat untuk memiliki kediaman dan rumah peristirahatan di dataran tinggi menyebabkan pembangunan di daerah lereng tidak dapat di hindari lagi. Daerah seperti ini sangat rentan terhadap keruntuhan atau longsor yang dapat menimbulkan berbagai kerugian, untuk itu kestabilan lereng yang akan digunakan perlu di teliti. Lereng yang terletak di jalan Selat Karimata belakang Hotel Pilihan Kota Sorong merupakan salah satu area yang letaknya di atas permukiman warga dan merupakan suatu akses jalan yang biasa dilewati oleh warga sekitar. Ruas jalan ini memiliki sisi yang berada tepat di atas lereng yang bisa mengakibatkan terjadinya keruntuhan tanah pada lereng tersebut. Analisis stabilitas lereng perlu dilakukan untuk mengetahui tingkat keamanan dari lereng tersebut agar warga yang bermukim di sekitar lereng dapat mendapat informasi yang akurat agar bisa merasa aman atau mengambil tindakan lebih lanjut jika lereng tersebut ternyata tidak stabil.

\section{Tujuan Penelitian}

1. Untuk menganalisi stabilitas lereng dengan cara perhitungan manual

2. Untuk menganalisis stabilitas lereng dengan menggunakan program GEO5

\section{STATE OF THE ART}

Adapun penelitian terdahulu yang terkait dengan penelitian ini adalah sebagai berikut :

\section{Tri Sadono (2017)}

Penelitian tentang Analisis Stablitas Lereng Dengan Program GEO5 Dan X STABL yang berada di Boyolali, Semarang, dan Temanggung. Dari penilitian ini didapatkan hasil-hasil sebagai berikut:

a. Dari hasil analisis program GEO5 nilai angka aman yang paling besar terjadi pada variasi bidang longsor V sebesar 1,71 .

b. Dari kelima variasi yang dianalisis dengan program GEO5 analisis lereng pada variasi I, II, III, IV, hasilnya tidak aman $(\mathrm{F}<1,5)$ dan analisa lereng pada variasi longsor $\mathrm{V}$ hasilnya aman $(\mathrm{F}>1,5)$.

\section{Violetta Gabriella Margaretha (2014)}

Penelitian tentang Analisis Stablitas Lereng Dengan metode fellenius di kawasan Citraland. Dari penilitian ini didapatkan hasil-hasil sebagai berikut:

a. Dari hasil analisis perhitungan komputer menggunakan program Slide 6 menunjukkan nilai Faktor Keamanan dari lereng di Kawasan Citraland adalah 0,193. Itu berarti lereng di Kawasan Citraland tersebut dalam kondisi tidak stabil. Itu berbahaya dan dapat mengakibatkan longsor pada kemudian hari.

b. Dari grafik hubungan FK vs $\alpha$, didapat hubungan bahwa semakin besar nilai sudut kemiringan lereng maka semakin kecil nilai faktor keamanan. Itu artinya semakin curam lereng maka kondisinya semakin tidak aman.

c. Dari grafik hubungan FK vs c \& Ø didapat hubungan bahwa semakin besar nilai c \& $\varnothing$ maka semakin besar nilai faktor keamanan yang didapat. Sedangkan untuk FK vs $\gamma$ didapat hasil sebaliknya bahwa semakin besar nilai $\gamma$ maka didapat nilai faktor keamanan yang semakin kecil.

d. Untuk grafik hubungan FK vs NS (dalam hal ini nilai NS yg dimasukkan 1-5) didapat hubungan bahwa semakin bertambah jumlah anak tangga maka nilai FK akan naik namun kemudian akan menurun.

e. Supaya keadaan lereng menjadi stabil dan Faktor Keamanan dapat menjadi lebih dari 1 maka lereng diperbaiki dengan menggunakan soil nail. Soil nail adalah salah satu cara perbaikan lereng dengan cara memperkecil gaya penggerak atau momen penyebab longsor. Sehingga dapat diperoleh nilai Faktor Keamanan 1,926 yang menunjukkan kondisi lereng dalam keadaan stabil. 
3. Giwa Wibawa Permana (2016)

Penelitian tentang Analisis Stabilitas Lereng Dan Penanganan Longsoran Menggunakan Metode Elemen Hingga PLAXIS V.8.2 Di Ruas Jalan Liwa - Simpang Gunung Kemala STA.263+650). Dari penelitian ini didapatkan hasil-hasil sebagai berikut:

a. Karakterisktik dan parameter tanah lereng sangat berpengaruh terhadap hasil analisis stabilitas lereng.

b. Kondisi muka air tanah baik pada kondisi kering, jenuh penuh, ataupun jenuh sebagian mempengaruhi besaran nilai faktor aman lereng.

c. Dari kedua hasil analisis stabilitas lereng dengan menggunakan rumus tak terhingga dan metode Plaxis terdapat perbedaan nilai faktor aman yang berbeda, faktor aman dengan rumus cenderung memiliki nilai lebih kecil dibandingkan dengan menggunakan Plaxis, hal ini dikarenakan analisis dengan menggunakan rumus tidak memasukkan parameter modulus elastisitas tanah dan angka poisson serta tinjauan lereng hanya ditinjau pada area bidang longsor saja.

d. Nilai faktor aman (Fs) hasil analisis stabilitas lereng :

- Analisis metode rumus tak terhingga :

1. Kondisi kering $=0,308$

2. Kondisi jenuh penuh $=0,268$

3. Kondisi jenuh sebagian $=0,153$

- Analisis metode program Plaxis :

1. Kondisi kering $=0,3872$

2. Kondisi jenuh penuh $=0,3566$

3. Kondisi jenuh sebagian $=0,2847$

- Hasil analisis setelah penanganan lereng metode program Plaxis sebesar 1,3548.

- Penanganan kelongsoran lereng meningkatkan nilai faktor aman lereng dan menurunkan deformasi lereng yang terjadi sehingga menjadi lebih aman dan lereng berada pada kondisi stabil.

\section{METODE}

\section{Tahapan Penelitian}

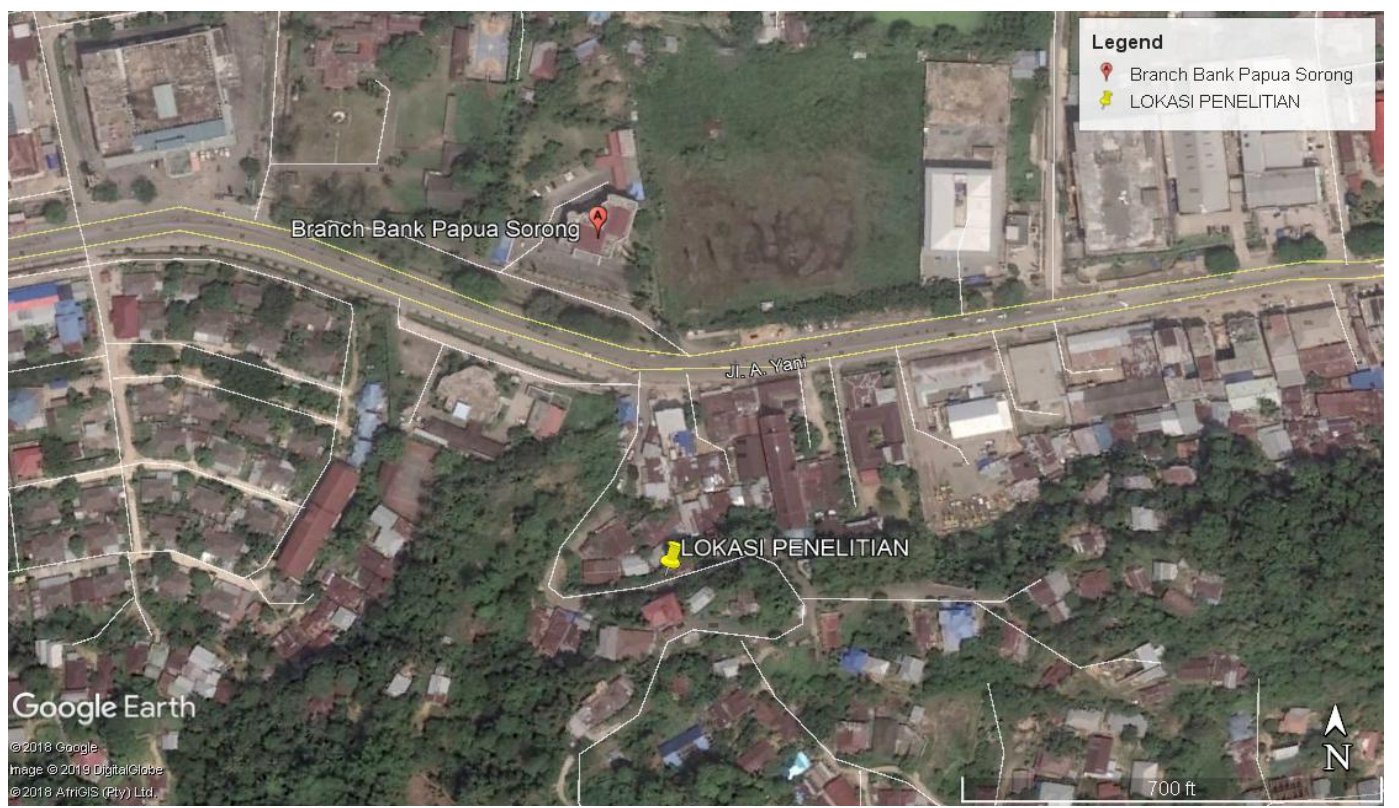

Tahapan penelitian yang digunakan adalah sebagai berikut :

1. Mengumpulkan data-data lapangan dan data laboratorium untuk perhitungan

2. Menghitung stabilitas dinding penahan terhadap penggeseran, penggulingan serta daya dukung tanah secara manual

3. mengontrol faktor aman dinding penahan tanah terhadapn penggeseran penggulingan dan daya dukung tanah secara manual 
4. menganalisis stabilitas dinding penahan tanah dengan menggunakan program Geo5

5. Kontrolstabilitas dinding penahan tanah dengan program Geo5.

Semua metode penulisan dan analisa dalam artikel ilmiah ini merujuk pada panduan penulisan tugas akhir Fakultas Teknik Universitas Muhammadiyah Sorong tahun 2014 (Pristianto, Amri, \& Rusdi, 2014). 


\section{REFERENSI}

1. Tri Sadono (2017). tentang Analisis Stablitas Lereng Dengan Program GEO5 Dan X STABL. Universitas Surakarta.

2. Violetta Gabriella Margaretha (2014). Analisis Stablitas Lereng Dengan metode fellenius di kawasan Citraland. Universitas Sam Ratulangi Manado.

3. Giwa Wibawa Permana (2016). Analisis Stabilitas Lereng Dan Penanganan Longsoran Menggunakan Metode Elemen Hingga PLAXIS V.8.2 Di Ruas Jalan Liwa - Simpang Gunung Kemala STA.263+650).

4. Hardiyatmo, C.H. (2006). Mekanika tanah 1

5. Ir. .ROKHMAN,MM. "Modul Praktikum Mekanika Tanah” Universitas Muhammadiyah Sorong

6. Pristianto, H., Amri, I., \& Rusdi, A. (2014, May 9). Pedoman Penulisan Tugas Akhir Fakultas Teknik Universitas Muhammadiyah Sorong 2014. http://doi.org/10.17605/OSF.IO/4VTJM. 